\title{
Educação das relações étnico-raciais no Brasil: paradoxos e obstáculos
}

\author{
Education of ethnic-racial relations in Brazil: paradoxes and \\ obstacles
}

\section{Educación de las relaciones étnico-raciales en Brasil: paradojos y obstáculos}

\section{Telmo Marcon'}

Universidade de Passo Fundo, Professor e Pesquisador no Programa de Pós-Graduação em Educação

\section{Iuan Penteado Dourado 2}

Universidade de Passo Fundo, Professor de Sociologia

Resumo: 0 artigo trata da educação das relações étnico-raciais, temática extremamente relevante do ponto de vista social e das políticas educacionais. 0 enfoque dado destaca elementos que se constituem em precondição para avançar no debate sobre o tema em instituições educativas. Fundamenta-se, aqui, a tese de que persistem na sociedade brasileira inúmeros preconceitos sociais e étnico-culturais que obstaculizam um debate transparente e democrático. Para dar conta desse desafio, destacamse os paradoxos que perpassam a formação sociocultural e política da sociedade brasileira, algumas formas de reprodução de preconceitos raciais na atualidade e, por fim, alguns obstáculos que dificultam um diálogo e a democratização efetiva da sociedade brasileira.

Palavras-chave: Relações étnico-raciais. Políticas educacionais. Preconceito. Democracia. Educação emancipadora.

Abstract: This article deals with the education of ethnic-racial relations, an extremely important theme from the social point of view as well as from educational policies. The approach used highlights elements constituting a precondition to advance in the debate about them in educational institutions. Here is founded the thesis that uncountable social and ethnic-racial preconceptions persist, hindering a transparent and democratic debate in the Brazilian society. In order to deal with this challenge, paradoxes that permeate the sociocultural and political formation of the Brazilian society, some forms

Doutor em História Social pela Pontificia Universidade Católica de São Paulo (PUC/SP); Mestre em História pela Universidade de Brasilia (UnB); https://orcid.org/0000-0002-9110-3210; http://lattes.cnpq.br/7659184664426945.

2 Mestre em Ciências Sociais pela Pontifícia Universidade Católica do Rio Grande do Sul (PUC/RS); Doutorando em Educação pela Universidade de Passo Fundo; https://orcid.org/0000-0002-4529-831X, http://lattes.cnpq.br/7379643381730867. 
of reproduction of actual racial preconceptions and, finally, some obstacles that hamper the dialogue and the effective democratization of the Brazilian society.

Keywords: Ethnic-racial relations. Educational policies. Preconception. Democracy. Emancipating education.

Resumen: El artículo aborda la educación de las relaciones étnico-raciales, temática extremadamente relevante desde el punto de vista social y de las políticas educativas. El enfoque dado destaca elementos que se constituyen en precondición para avance en el debate sobre el tema en instituciones educativas. Se fundamenta aquí la tesis que persisten en la sociedad brasileña innumerables prejuicios sociales y étnico-culturales que obstaculizan un debate transparente y democrático. Para dar cuenta de este desafío, se destacan las paradojas que atraviesan la formación sociocultural y política de la sociedad brasileña, algunas formas de reproducción de prejuicios raciales en la actualidad y, por último, se destacarán algunos obstáculos que dificultan un diálogo y la democratización efectiva de la sociedad brasileña.

Palavras clave: Relaciones étnico-raciales. Políticas educativas. Preconcepto. Democracia. Educación emancipadora.

\section{CONSIDERAÇÕES INTRODUTÓRIAS}

A delimitação proposta no presente artigo contempla a discussão de elementos históricos e sociológicos que ajudam a compreender os obstáculos com relação ao avanço das discussões sobre a educação das relações étnico-raciais na sociedade brasileira e, particularmente, nas instituições educativas. Problematizam-se questões que ajudam a analisar porque persistem práticas sociais racistas e xenofóbicas que negam a diversidade étnico-cultural e, consequentemente, excluem grupos sociais, comprometendo o avanço não apenas das discussões teóricas, mas também das mudanças de comportamentos e pensamentos racistas e simplificadores. Compreender as formas como se reproduzem preconceitos na sociedade brasileira é condição fundamental para o entendimento das resistências em reconhecer a diversidade cultural e o aprofundamento das questões postas pelas políticas de educação das relações étnico-raciais. 
As argumentações que serão apresentadas têm como objetivo fundamentar a tese que persistem na sociedade brasileira preconceitos raciais que obstaculizam um debate transparente e democrático, especialmente quando se tratam de indígenas e negros, mas que se estende também a outros grupos sociais excluídos. Falas de professores que atuam na educação básica e frequentam a educação superior dão conta das resistências em debater questões étnico-culturais e preconceitos raciais nas escolas. 0 mesmo fenômeno observa-se em espaços universitários. Essas resistências expressam-se, por vezes, por meio de contestações explícitas, mas, em outras circunstâncias, de forma velada ou mesmo pelo silenciamento.

Como essa problemática vem sendo tratada na sociedade brasileira? Do ponto de vista legal, ocorreram avanços importantes desde a Constituição de 1988 que, em seu Preâmbulo, trata da necessidade de "instituir um Estado Democrático, destinado a assegurar o exercício dos direitos sociais e individuais, a liberdade, a segurança, o bem-estar, o desenvolvimento, a igualdade e a justiça como valores supremos de uma sociedade fraterna, pluralista e sem preconceitos [..."' (BRASIL, 1988). No art. $3^{\circ}$ do Texto Constitucional, destacamse vários objetivos da República brasileira, entre os quais, conforme inciso IV, o de "promover o bem de todos, sem preconceitos de origem, raça, sexo, cor, idade e quaisquer outras formas de discriminação." (BRASIL, 1988). A LDB (BRASIL, 1996) reafirma os pressupostos expressos na Constituição. 0 art. $3^{\circ}$ estabelece vários princípios que orientarão o ensino, entre os quais, o inciso IV que se refere ao "respeito à liberdade e apreço à tolerância." No parágrafo $4^{\circ}$ do artigo 26, que trata dos currículos do ensino fundamental e médio, afirma que, no estudo de História do Brasil, deverão ser levadas em consideração "as contribuições das diferentes culturas e etnias para a formação do povo brasileiro, especialmente das matrizes indígena, africana e européia." (BRASL, 1988). Esse mesmo art. 26 da LDB foi objeto de complementação com a Lei n. 10.639, de 9 de janeiro de 2003 (BRASIL, 2003), passando a constituir o art. 26-A, determinando que "nos estabelecimentos de ensino fundamental e médio, oficiais e particulares, torna-se obrigatório o ensino sobre História e Cultura Afro-Brasileira." № $\S 1^{\circ}$ do mesmo artigo, lê-se que o conteúdo a que se refere o artigo "incluirá o estudo da História da África e dos Africanos, a luta dos negros no Brasil, a cultura negra brasileira e o negro na formação da sociedade nacional, resgatando a contribuição do povo negro nas áreas social, econômica e política pertinentes à História do Brasil." (BRASIL, 2003). Ainda, segundo o art. 79 da LDB, "A União apoiará técnica e financeiramente os sistemas de ensino no provimento da educação intercultural às comunidades indígenas, desenvolvendo programas integrados de ensino e pesquisa." (BRASIL, 1996).

Essas breves considerações evidenciam que há um amparo legal reconhecendo a diversidade étnico-cultural compreendida como constitutiva da sociedade brasileira e a necessidade da educação escolar trabalhar essas temáticas e potencializar a riqueza da interculturalidade. Não obstante esses avanços, ainda persistem obstáculos socioculturais e 
econômicos que impedem uma democratização efetiva da sociedade brasileira. Do ponto de vista teórico, como a tradição sociológica crítica identifica e analisa esses obstáculos?

\section{AS CONTRADIÇÕES DA SOCIEDADE BRASILEIRA E AS EXPLICAÇÕES SOCIOLÓGICAS}

A tese que fundamentamos e defendemos neste artigo é que somente é possivel compreender as desigualdades socioeconômicas existentes no Brasil analisando a sua formação histórica e o papel que a escravidão cumpriu e ainda cumpre no pensamento brasileiro. Sem levar em consideração essas relações e os obstáculos da sociedade brasileira, particularmente o lugar do negro, a educação das relações étnico-raciais não alcançará os seus objetivos. É evidente que não se trata de uma questão envolvendo apenas o negro, mesmo que ele tenha sido o principal protagonista na configuração da Lei n. 10.639 (BRASIL, 2003), mas diz respeito a questões estruturais da sociedade brasileira. Hoje, não existe formalmente uma lei que dê amparo à escravidão, no entanto, a reprodução de práticas que remetem ao regime escravocrata continua a fazer parte da realidade de muitos brasileiros. A fundamentação desse argumento pode ser buscada em diferentes fontes, entre as quais, as estatísticas. Os dados da exclusão de negros em espaços educacionais, em postos de trabalho e nos salários são incontestáveis.

Os dados do IBGE do período entre 2008 e 2010 apontam para uma população de aproximadamente 190 milhões de pessoas no Brasil, sendo que, destas, 97 milhões declararam-se pretas e pardas e 91 milhões autodeclararam-se brancas, além dos 0,7\% que se declararam indígenas (IBGE, 2010). Em 2008, o Instituto de Pesquisa Econômica Aplicada (IPEA) publicou pesquisas mostrando que $8,5 \%$ da população brasileira mais pobre vivia com uma renda inferior a $\mathrm{R} \$ 70,00$ por mês. Desse total, 70\% eram negros. Além disso, $63 \%$ da população que vivia abaixo da linha da pobreza eram negros, o mesmo ocorrendo com $70 \%$ dos que vivem abaixo da linha da indigência. Entre os $10 \%$ dos mais pobres no Brasil, $65 \%$ são negros, enquanto dos $10 \%$ mais ricos, $86 \%$ declaram-se brancos (INSTITUTO DE PESQUISA ECONÔMICA APLICADA, 2008). ${ }^{3}$

Dados que constam no Mapa da Violência 2013: Homicídios e Juventude no Brasil (WAISELFISZ, 2013) reafirmam a enorme desigualdade entre brancos e negros. Com relação aos assassinatos no Brasil, por exemplo, os negros e pardos totalizam 71,4\% das vítimas. 
0 que alguns denominam "genocídio negro brasileiro" evidencia que o perfil da maioria dos assassinados é jovem negro, sexo masculino, com idades entre 14 e 25 anos. Ainda, segundo dados do Mapa da Violência 2015, no capítulo $A$ cor das vítimas, há uma redução de homicídios por arma de fogo contra pessoas brancas (queda de 27,1\% em relação à pesquisa de 2013), enquanto o número de homicídios por arma de fogo contra pessoas negras aumentou 9,9\%. Fazendo-se um comparativo, observa-se que, em 2013, a vitimização de pessoas negras representava 71,7\% do total (WAISELFISZ, 2015, p. 81-87).

Quando se trata de rendimento salarial, as desigualdades também são gritantes e podem ser auferidas a partir da classificação negro/pardo e branco. Tomando os dados do rendimento médio no Brasil medido em seis grandes regiões metropolitanas com base no critério de classificação de cor branca e preta/parda, temos o seguinte quadro, segundo dados do IBGE (2013): em 2003, os de cor branca recebiam em média ( $\mathbf{R}$ 1.875,19), 51,58\% a mais do que os de cor preta/parda ( $R \$$ 907,98); em 2013, essa diferença caiu para 42,64\% ( $R \$$ 2.396,74 para os de cor branca e $\mathbf{R} \$ 1.374,79$ para os de cor preta/parda). Mesmo havendo uma importante redução das diferenças, elas continuam abismais.

Esses breves indicadores revelam que ainda existem desigualdades profundas que poderiam ser auferidas em outros dados sobre evasão escolar; trabalho precarizado; acesso ao consumo de alimentos; outras formas de violência; etc. Por que essas desigualdades persistem e que explicações foram e estão sendo dadas? São inúmeros os fatores que intervêm nesses processos, mas para a presente discussão serão destacadas as contribuições de dois sociólogos brasileiros: Florestan Fernandes e Jessé Souza. Eles ajudam-nos a construir um diagnóstico da sociedade brasileira e os paradoxos que perpassam a sua constituição e o seu desenvolvimento social, econômico, político e étnicocultural. Ajudam, também, a desconstruir os mitos de "democracia racial" e de "igualdade de oportunidades", baseados no conceito de meritocracia, bem como das questões estruturais do racismo brasileiro. Dessa forma, é possível compreender melhor as particularidades da modernidade periférica brasileira, perspectiva desenvolvida por Souza (2012), bem como as peculiaridades da "revolução burguesa" no Brasil e a precária "integração do negro na sociedade de classes", objetos das pesquisas de Florestan Fernandes.

Apesar do reconhecimento que pobreza e negritude são geradores de preconceitos distintos, necessitando ser estudados separadamente, na realidade brasileira, esses dois fatores andam juntos. Ser negro e pobre é uma realidade marcante. Essa combinação acaba por esconder a sobreposição e o peso de um ou outro desses fatores quando analisados em separado. Da mesma forma, os fatores que geram preconceitos se agravam, quando, junto aos dois, somarmos o fato de a pessoa ser mulher, homossexual ou possuir algum tipo de deficiência. 


\subsection{A FORMAÇÃO DA SOCIEDADE BRASILEIRA E A HERANÇA ESCRAUOCRATA: CONTRIBUIÇÕES DE FLORESTAN FERNANDES}

As contribuições de Fernandes visam aqui ampliar os entendimentos sobre a inclusão dos negros na sociedade brasileira. Quais os elementos históricos, políticos e sociais que impedem a consolidação de uma política de igualdade efetiva no País? Uma das questões investigadas por Florestan Fernandes foi o papel da escravidão na formação da sociedade brasileira. Evidentemente, existem outros elementos que estão na gênese e perpassam o desenvolvimento socioeconômico, político e cultural da sociedade brasileira, entre os quais, a forma como foi colonizada, os interesses da metrópole em extrair riquezas, entre outros fatores. No entanto, para Fernandes, a escravidão é entendida não apenas como relação de trabalho, mas, principalmente, como constitutiva de uma cultura escravocrata autoritária.

A escravidão no Brasil, mesmo assumindo identidades distintas nos diferentes contextos espaciais, socioeconômicos e políticos, tem como característica central as relações verticalizadas e autoritárias entre senhor e escravo e a violência como forma de reprimir comportamentos e práticas consideradas inaceitáveis pela cultura senhorial e jurídica. 0 que se pretende depreender dessas relações são as formas autoritárias que não foram superadas com o fim do regime escravocrata. Não é por acaso que ainda no século XXI continuem sendo denunciadas relações de trabalho análogas à da escravidão. ${ }^{4}$ Dados do Observatório Digital do Trabalho Escravo no Brasil, ${ }^{5}$ estimam que entre 1995 e 2017 mais de 50 mil pessoas foram resgatadas em condições semelhantes à escravidão (SMARTLAB, 2017). É possível que esse número seja ainda maior, já que todos os anos novos casos são revelados.

Como as ciências sociais explicam esse fenômeno? Não é objetivo dar conta de todos os elementos envolvidos nessa discussão, que é muito complexa. No entanto, as contribuições de Fernandes (1975, 1978a, 1978b) ajudam a problematizar parte dessas questões. Uma primeira dimensão diz respeito à compreensão que Fernandes (1975) tem da revolução burguesa no Brasil. Distintamente de outros contextos, especialmente na Europa,

40 conceito de trabalho análogo ao escravo procura dar conta das novas formas de escravidão, não mais permitido por lei desde a Lei Áurea de 13 de maio de 1888. Desde então, o Estado brasileiro não tolera mais a propriedade de uma pessoa por outra, ou seja, é uma prática ilegal. De acordo com o artigo 149 do Código Penal Brasileiro (BRASIL, 1940), os elementos que caracterizam o trabalho análogo ao escravo são: condições degradantes de trabalho; jornada exaustiva, trabalho forçado e servidão por divida. Esses elementos podem estar juntos ou separadamente.

5 O Banco de dados Observatório Digital do Trabalho Escravo no Brasil (ODTEB) foi criado pelo SmartLab, envolvendo uma parceria do Ministério Público do Trabalho (MPT) com a Organização Internacional do Trabalho (OIT). 
onde a ascendente classe burguesa trava embates contra a nobreza e a aristocracia, no Brasil, é a mesma classe dominante que comanda a passagem das relações de trabalho escravocrata para o trabalho assalariado e livre. No Brasil, são dois movimentos que ocorrem concomitantemente: o fim da escravidão e a revolução burguesa. Essa passagem, é preciso destacar, não foi tranquila e sem contradições ou tensões internas. No entanto, a classe dominante conservadora conseguiu neutralizar os movimentos progressistas que lutavam pelo fim da escravidão ainda no século XVIII. Nesse sentido, Fernandes assinala que a revolução burguesa resultou, no caso brasileiro, muito mais de ajustes da classe dominante do que da luta revolucionária da burguesia para chegar ao poder como ocorreu na Europa, especialmente na França. Ele apresenta vários argumentos e questões que fazem parte da plataforma burguesa no Brasil na luta para dar uma nova dinâmica ao capitalismo.

A burguesia brasileira, mesmo se constituindo como classe, não pode ser pensada de forma homogênea. As transformações que resultam na expansão de cidades que dinamizam, entre outros aspectos, o comércio, fizeram com que alguns senhores rurais se projetassem em novos cenários econômicos e também em espaços políticos na Corte ou em governos provinciais. Isso produziu, segundo Fernandes (1975, p. 27-28):

0 solapamento progressivo do tradicionalismo vinculado à dominação patrimonialista começou a verdadeira desagregação econômica, social e política do sistema colonial. Essa porção de senhores rurais tendeu a secularizar suas idéias, suas concepç̃̃es políticas e suas aspirações sociais; e, ao mesmo tempo, tendeu a urbanizar, em termos ou segundo padrões cosmopolitas, seu estilo de vida, revelando-se propensa a aceitar formas de organização da personalidade, das ações ou das relações sociais e das instituições econômicas, jurídicas e politicas que eram malvistas e proscritas no passado.

Essas transformações não chegam a provocar mudanças nas relações sociais e culturais de dominação. Como afirma o próprio Fernandes (1975, p. 29), esse espírito burguês não exige "a defesa implacável dos direitos do cidadão." Como bem observa, as mudanças políticas que ocorreram com a independência e outros movimentos políticos não resultaram em transformações mais profundas nos âmbitos econômico, cultural e social.

A independência foi naturalmente solapada como processo revolucionário, graças ao predomínio de influências histórico-sociais que confinavam a profundidade da ruptura com o passado. 0 estatuto colonial foi condenado e superado como estado jurídico-político. 0 mesmo não sucedeu com o seu substrato material, social e moral, que iria perpetuar-se e servir de suporte à construção de uma sociedade nacional. (FERNANDES, 1975, p. 33). 
Nos dois volumes da obra $A$ integração do negro na sociedade de classes (FERNANDES, 1978a, 1978b), o autor busca elementos em diferentes fontes de pesquisa (jornais, depoimentos, registros) para analisar o drama de ex-escravos que foram libertos, por força da Lei da Abolição, mas ficaram literalmente jogados à própria sorte. Dados e depoimentos produzidos sobre o período e a análise sociológica proposta dão conta que muitos negros que saíram da condição de escravatura acabaram retornando aos seus antigos senhores em busca de abrigo para sobreviver. Esse fenômeno decorre, em parte, da ausência de políticas públicas que produzissem uma reforma agrária, por exemplo, no campo, bem como da falta de condições para a sobrevivência em espaços urbanos.

\begin{abstract}
Os senhores foram eximidos de responsabilidade pela manutenção e segurança dos libertos, sem que o Estado, a lgreja ou qualquer outra instituição assumissem encargos especiais, que tivessem por objeto prepará-los para o novo regime de organização da vida e do trabalho. 0 liberto viu-se convertido, sumária e abruptamente, em senhor de si mesmo, tornando-se responsável por sua pessoa e por seus dependentes, embora não dispusesse de meios materiais e morais para realizar essa proeza nos quadros de uma economia competitiva. (FERNANDES, 1978a, p. 15).
\end{abstract}

0 fim da condição de escravo não representou, para grande parte desses sujeitos, uma vida melhor. Assim, segundo define Fernandes (1978a, p. 20): "a sociedade brasileira largou o negro ao seu próprio destino, deitando sobre seus ombros a responsabilidade de reeducarse e de transformar-se para corresponder aos novos padrões e ideais de homem, criados pelo advento do trabalho livre, do regime republicano e do capitalismo." As novas relações de trabalho emergentes desde a segunda metade do século XIX, baseadas no trabalho livre e na presença do imigrante europeu, impactaram profundamente a vida do negro. Em parte, Fernandes (1978a, p. 26) explica por que o negro e o mulato "foram eliminados das posições que ocupavam no artesanato urbano pré-capitalista ou no comércio de miudezas e de serviços, fortalecendo-se de modo severo a tendência a confiná-lo a tarefas ou ocupações brutas, mal retribuídas e degradantes." Os dados apontados anteriormente sobre as diferenças salarias ainda refletem essas contradições no século XXI. Para além disso, existem outros dois fatores importantes a serem observados aqui: a postura de negros e mulatos de lutar pela liberdade de escolha e "decidir como, quando e onde trabalhar" (FERNANDES, 1978a, p. 29) e a disputa por postos de trabalho com o imigrante, visto que, segundo Fernandes (1978a, p. 27, grifo do autor), "onde o imigrante aparecesse, eliminava fatalmente o pretendente negro ou mulato, pois entendia-se que ele era o agente natural do trabalho livre."

Para além desses desdobramentos históricos concretos, existem as interpretações que foram produzidas a respeito do processo de modernização, bem como das relações interpessoais e étnico-culturais. Discursos produzidos no ambiente acadêmico por parte de 
intelectuais brasileiros trataram de esconder e mitificar a exclusão dos negros na sociedade brasileira, construindo ideologias pautadas em representações conhecidas como a do "homem cordial", da "democracia racial", da "brasilidade verde-amarela". Ao serem descoladas das relações sociais e econômicas estruturais, essas representações acabaram por naturalizar e sustentar a exclusão "cientificamente" com discursos definidos como "racismo científico".

Em síntese, Fernandes (1978a, p. 15) sustenta a tese que a "desagregação do regime escravocrata e senhorial operou-se, no Brasil, sem que se cercasse a destituição dos antigos agentes de trabalho escravo de assistência e garantias que os protegessem na transição para o sistema de trabalho livre."

\subsection{A MODERNIDADE PERIFÉRICA BRASILEIRA NA PERSPECTIUA DE JESSÉ SOUZA}

Jessé Souza parte de uma crítica às representações que foram produzidas por intelectuais brasileiros conservadores, especialmente Sérgio Buarque de Holanda, Gilberto Freire e Raymundo Faoro. Souza (2012, p. 19) propõe o seguinte desafio intelectual:

Como perceber a singularidade 'relativa' de toda formação social nacional, com uma história especifica, sem cair na armadilha da singularidade 'absoluta' construída para fins pragmáticos do 'culturalismo nacional'? [...] Como reconstruir as bases de uma ciência social alternativa e verdadeiramente crítica que não obscureça, mas, ao contrário, explicite os conflitos sociais e as dores humanas silenciadas?

Antes mesmo de apresentar respostas teóricas a esse desafio, Jessé Souza, mesmo com algumas críticas pontuais, retoma as ideias de Florestan Fernandes, identificando a revolução burguesa no Brasil como elemento fundamental para compreender o processo de modernização no País. Nela, ocorreram mudanças nas regras do jogo político e econômico, mas sem alterar as posições dos atores sociais (elite escravocrata e hegemonicamente agrária), nem mudanças culturais e, principalmente, estruturais. Expresso em outros termos, preservaram-se a forma de pensar, a moralidade e as relações de dominação e poder. A dimensão social foi absorvida por uma lógica de mercado combinada com a manutenção da hierarquia social existente. Permanecem as discriminações raciais e os apegos à família patriarcal ${ }^{6}$ que se prolongam aos dias atuais. Esses valores são consolidados como verdades

6 É possível observar, em determinados contextos brasileiros, a importância do sobrenome e a origem familiar como critérios para julgar uma pessoa. 0 sobrenome do patriarca é ainda um definidor social forte no status conferido ao individuo. 
e, ao serem naturalizados, agregam-se a um conjunto de elementos fundamentais que ajudam a compreender determinadas realidades e comportamentos sociais no contexto brasileiro (SOUZA, 2012).

Ademais, segundo Souza (2012), o liberalismo instalou-se no Brasil com particularidades, principalmente no contexto da abolição da escravidão. Os negros constituíam, em meados do século XIX, cerca de dois terços da população brasileira. Nesse contexto, as elites promovem mudanças no regime de trabalho escravocrata para o regime assalariado, mas sem rupturas profundas, ou como afirma Souza (2012, p. १२2), faz-se uma "revolução social de brancos para brancos, leia-se, um compromisso intraelite, inaugurando, daí, um abandono secular de uma 'ralé' despreparada para enfrentar as novas condições socioeconômicas."

Esse processo recebe várias denominações, sendo que Souza (2012) identifica como "modernização periférica brasileira", Fernandes (1975) chamou de "revolução encapuzada", Vianna (1997) trata de "revolução passiva" e Carvalho (1987) refere-se aos "bestializados". Em outros termos, nosso passado colonial apresenta algumas características estruturais que foram atingidas pela modernização, mas sem que houvesse uma revolução nos valores e nas relações de poder, marginalizando um enorme contingente social, principalmente negros. Os senhores de escravos passaram a desempenhar outras funções sociais, políticas e econômicas, muitos deles se tornando barrões do café. Segundo o IBGE (1986), estima-se que - Brasil recebeu, entre 1531 e 1850, aproximadamente quatro milhões de africanos. Em 1890, dois anos após a abolição, segundo o senso daquele período, havia 2,1 milhões de pretos e 4,6 milhões de mestiços, ou seja, aproximadamente $47 \%$ da população brasileira.

Um dos pontos estruturantes da abordagem de Jessé Souza é a sua crítica às interpretações produzidas sobre a sociedade brasileira por intelectuais conservadores, responsáveis pela fundação de uma teoria sociológica sobre a identidade nacional, a caracterização do brasileiro e as relações entre as culturas. Gilberto Freyre (1900-1987) e Sérgio Buarque de Holanda (1902-1982) realizaram um movimento teórico que constituiu uma espécie de revolução simbólica. Esses pensadores trouxeram perspectivas teóricas que cumpriram um importante papel, porém, mais político e ideológico do que científico.

Souza (2012) denomina essas teorias, de forma provocativa e crítica, de "conto de fadas para adultos" ou, mais objetivamente, de "sociologia da inautenticidade". Em grande medida, as propostas de Holanda e Freyre, segundo essa crítica, constituem uma sociologia que tentou engajar a população brasileira em uma causa comum acerca de uma identidade do Brasil, uma tentativa de "união mitológica". Conforme Souza (2012, p. 15), "todo mito nacional bem-sucedido quer transmitir a ideia de "unidade substancial" entre todas as classes que constituem uma sociedade. É um mito no sentido de que é uma 'fantasia' para fins programáticos de produção de solidariedade social." Essa mesma discussão é feita por Chauí (2004) ao problematizar em sua obra Brasil: mito fundador e sociedade autoritária os 
pressupostos que serviram de base para a construção de mitos relativos ao povo brasileiro como ordeiro, pacífico e generoso.

A contribuição de intelectuais na explicação da identidade de um povo passa pelo entendimento sobre a sua construção. Gilberto Freyre, por exemplo, resgata uma perspectiva muito forte em seu tempo, chamada, posteriormente, de forma crítica, de "racismo científico". Ele propõe uma inversão na ideia até então dominante que a culpa pelo atraso brasileiro se devia à mestiçagem do povo. Em suas obras, Casa-Grande \& Senzala (FREYRE, 1987) e os três volumes de Sobrados e Mucambos (FREYRE, 1951a, 1951b, 1951c), o mestiço transforma-se no símbolo máximo da brasilidade, prova concreta de uma democracia racial brasileira.

Sérgio Buarque de Holanda, em uma de suas obras mais famosas, que é Raízes de Brasil (2015), produz uma representação sustentada na ideia de um homem cordial, nesse caso, oposta ao individualismo ascético do protestante norte-americano. Holanda (2015) identifica uma herança ibérica de forte influência personalista na formação do brasileiro, sujeito emotivo e apegado a valores tradicionais pessoalizados e patrimonialistas.

A criação de um "mito de brasilidade" por esses intelectuais influenciou a formação do Estado brasileiro, bem como de outras instituições políticas e sociais. Essa perspectiva desviou o foco da exclusão do negro na sociedade de classes e o abismo social consolidado entre os diferentes grupos étnicos. Para Souza (2012), essas perspectivas teóricas não respeitaram um conjunto de particularidades da modernização brasileira. Holanda e Freyre deram origem a uma tradição de pensamento que teve continuidade em intelectuais como Raymundo Faoro, Fernando Henrique Cardoso e Roberto DaMatta. ${ }^{7}$ Essa tradição possui em comum a ideia que seria possível identificar, na cultura brasileira, uma essência ou uma espécie de "espírito brasileiro".

0 "culturalismo" seja na versão personalista, seja na sua versão pseudocrítica patrimonialista, reproduz sempre o 'mito nacional' meramente transvestido de conceitos pseudocientíficos. Caberia a 'verdadeira ciência', no entanto, criticar todos os mitos e ilusões de senso comum. Como isso não é feito, somos presas fáceis de um debate pobre e conservador que tende a perpetuar consensos naturalizadores que reproduzem e legitimam todo o tipo de privilégio injusto. (SOUZA, 2012, p. 18).

Essa produção intelectual limitou, de certa forma, uma compreensão crítica das transformações econômicas, sociais e políticas em curso na sociedade brasileira desde o

Essa crítica não pode ser estendida a todas as obras publicadas por esses autores. As críticas feitas atualmente por Jessé Souza não negam as contribuições que esses intelectuais trouxeram. 
século XIX. Os negros acabaram constituindo a maior parte da ralé brasileira (SOUZA, 2016), como afirma Souza (2012). Ao serem libertos das correntes físicas e jurídicas da escravidão, ${ }^{9}$ viram-se presos às novas lógicas econômicas e sociais. Ancorado nas obras de Florestan Fernandes sobre A integração do negro na sociedade de classe (FERNANDES, 1978a, 1978b), Souza (2012, p. 155) reforça a ideia das limitadas possibilidades existentes para os negros.

Para o negro, sem a oportunidade de classificação social burguesa ou proletária, restava os interstícios e as franjas marginais do sistema como forma de preservar a dignidade de homem livre: o mergulho na escória proletária, no ócio dissimulado, ou, ainda, na vagabundagem sistemática e na criminalidade fortuita ou permanente.

0 resultado desse processo de "modernização brasileira" foi a produção social de classes subalternas que não conseguiram se integrar aos novos padrões e exigências, bem como a um conjunto de mecanismos sociais de naturalização da pobreza e da desigualdade estrutural. A base socioeconômica da pirâmide solidifica-se com a modernização periférica tendo cor e origem social. A naturalização desses processos faz com que a desigualdade e a miséria não sejam vistas como problemas sociais e estruturais, nem pela classe dominante, muito menos por boa parcela da intelectualidade brasileira conservadora. Dessa forma, resta ao povo negro e pobre criar alternativas de vida e sobrevivência de forma marginal. As várias pesquisas apresentadas na obra Ralé brasileira: quem é e como vive, organizada por Jessé Souza (2016), ajudam a compreender melhor quais são as alternativas de ascensão social para uma boa parcela da ralé: envolvimento com o tráfico ou prostituição.

\section{A REPRODUÇÃO DE PRECONCEITOS RACIAIS}

As questões até aqui pontuadas não têm como finalidade fazer uma mera reconstrução histórica, mas compreender que existem elementos que perpassam as diferentes temporalidades, mesmo que assumindo formas específicas de manifestação. Como as marcas da escravidão continuam produzindo práticas e relações socioculturais discriminadoras na atualidade? Essa questão não tem respostas simples. No entanto, é possível evidenciar algumas pistas no contexto da realidade brasileira.

8 Como afirma Jessé Souza, o termo ralé é usado de forma provocativa para dar conta dos grupos mais excluidos na sociedade brasileira, mas sem um status de conceito.

9 Uma espécie de escravidão interna, que alerta Florestan Fernandes, somada ao racismo e ao preconceito e exclusão dos negros, realizava um tipo de "prisão da própria mente", que os impede de pensar e agir dentro da ordem de uma nova sociedade (SOUZA, 2012, p. 153-163). 
Uma delas diz respeito ao papel da linguagem na reprodução, como afirma Bagno (2004), em "Preconceito linguístico". Para o autor, a linguagem é uma das formas sutis usadas para a reprodução de preconceitos e não tem sido criticada suficientemente na sociedade brasileira (BAGN0, 2004, p. 13). Conforme assinala o próprio Bagno (2004, p. 75), os preconceitos são reproduzidos no âmbito da linguagem e

impregnam-se de tal maneira na mentalidade das pessoas que as atitudes preconceituosas se tornam parte integrante do nosso próprio modo de ser e de estar no mundo. É necessário um trabalho lento, contínuo e profundo de conscientização para que se comece a desmascarar os mecanismos perversos que compõem a mitologia do preconceito.

Uma segunda forma articula-se aos discursos pautados no conceito de meritocracia. Críticos desse discurso, Bourdieu e Passeron (1970) ajudam a compreender como existem outros componentes que intervêm no sucesso ou fracasso social e escolar e que, em grande medida, tendem à reprodução social. ${ }^{10} \mathrm{~A}$ concepção dominante de meritocracia ampara-se na ideia que o sucesso depende estritamente do esforço individual. Bourdieu (1984) evidencia que existem profundas relações entre três tipos de capital: o econômico, o social e o cultural. Ele ajuda-nos a compreender como essas três formas de capital estão profundamente entrelaçadas, sem haver um determinismo de um sobre o outro. Assim, compreender as razões da exclusão social, econômica e cultural de grupos étnico-culturais implica um esforço de compreensão histórica e sociológica sobre como esses três tipos de capital se articularam (BOURDIEU, 1984).

0 que existe de mais simplificador nos discursos pautados na meritocracia é a negação da desigualdade econômica e cultural existente, bem como a sua gênese e a conformação histórica. As diferentes condições socioeconômicas, políticas e culturais estabelecem diferentes exigências em situações de competição. Desconsiderar a desigualdade econômica e social no acesso aos bens culturais e educacionais, tanto no espaço doméstico quanto nas instituições formais, e as suas implicações na definição de lugares e papeis sociais é próprio de posturas míticas. Diferente do "racismo científico" do passado, embora continue sendo mítico na atualidade, é porque está baseado na lógica do livre mercado. A base do discurso meritocrático é que todos possuem as mesmas chances, bastando esforço individual. Para sustentar essa ideia, são apresentados casos isolados de sucesso.

10 As pesquisas e as discussões mais atuais pontuam a ampliação dessa visão, ou seja, a forma como o individuo percebe a realidade não está diretamente relacionada à classe social que pertence, mas aos dispositivos culturais que têm a sua disposição, como desenvolve Pierre Bourdieu no conjunto de suas pesquisas. Uma ideia bem ilustrativa nesse sentido é a dominação simbólica que somente é possível se for alinhada por estruturas sociais já existentes. Nesse sentido, as lógicas de dominação precisam ser reconhecidas como legitimas pelos dominados (BOURDIEU; PASSERON, 1970; BOURDIEU, 2003; NOGUEIRA; CATANI, 1998). 
As pessoas que não atingem o dito sucesso, são, individualmente, responsáveis pelo próprio fracasso. A passagem de um racismo científico para o discurso meritocrático é denominada por Souza (2012, p. 94) de esquematização.

\begin{abstract}
Este ponto é central para o meu argumento [...] Precisamente o tema da 'esquematização' é que parece dar vazão às teorias essencialistas da cultura nas diversas e infinitas variações da teoria tradicional da modernização, inclusive nas suas variações 'hibridistas' em moda hoje em dia. [...] gerando uma confusão e indeterminação da análise que, muitas vezes, pela correspondência com a percepção inarticulada de preconceitos do senso comum, é precisamente uma das principais razões do seu poder de convencimento. (SOUZA, 2012, p. 94).
\end{abstract}

Outra forma bastante expressiva de preconceito se efetiva nas críticas endereçadas às políticas afirmativas, pautadas no conceito de discriminação positiva, como é o caso das cotas. Uma das críticas é que todos têm direitos iguais, conforme assegura a Constituição de 1988. A igualdade, no entanto, não pode se limitar ao princípio formal. Como ficam as desigualdades que são reais e perpassam a formação histórica brasileira e como chegam aos nossos dias? A Lei n. 10.639 (BRASIL, 2003) alterou a LDB e incluiu "no currículo oficial da Rede de Ensino a obrigatoriedade da temática História e Cultura Afro-Brasileira." Por que muitas escolas de educação básica e instituições de ensino superior ainda não democratizaram as propostas contidas nessa lei em seus espaços e resistem em discutir essas temáticas?

As explicações dessas posturas estão mais focadas nos desdobramentos formativos limitados de professores com relação ao passado do que na falta de vontade ou mesmo em um racismo incorporado por muitos educadores. É evidente que a formação de professores para discutir de modo democrático, crítico e aberto os temas vinculados à educação das relações étnico-raciais é fundamental. No entanto, essa formação não é suficiente, caso não consiga desconstruir as estruturas subjetivadas que continuam a discriminar determinados grupos sociais. As políticas educacionais e as legislações avançaram significativamente do ponto de vista formal. Isso não ocorreu com as mudanças culturais e as práticas sociais. Nesse sentido, é fundamental questionar os pressupostos que escamotearam as contradições socioeconômicas e culturais desde a gênese da formação histórica brasileira até os desdobramentos históricos, chegando aos tempos atuais. Por que ainda temos tantas dificuldades para lidar com questões envolvendo negros e índios nas escolas e nas instituições de educação superior? Muitas vezes essa discussão fica limitada ao Dia da Consciência Negra e ao Dia do Índio. Mais grave ainda é que, em muitos desses eventos celebrados nas escolas, nessas datas, reforçam mitos, naturalizam discriminações ou romantizam, especialmente quando se tratam de indígenas. 


\section{CONSIDERAÇÕES FINAIS}

No percurso deste artigo, foram apresentados argumentos em defesa da tese que as resistências em democratizar o debate sobre questões étnico-culturais e os preconceitos raciais têm como fatores mobilizadores a presença ainda muito forte de traços autoritários e discriminatórios herdados do período escravocrata. Muitos avanços foram conquistados desde a Abolição da Escravatura, especialmente com a Constituição de 1988 e os desdobramentos posteriores, sobretudo com as políticas sociais e as legislações educacionais que apontam para um conjunto de desafios a serem enfrentados pela sociedade. No entanto, as dificuldades em democratizar as discussões expressam resistências ainda presentes em instituições sociais e educativas e nas práticas sociais que negam a pluralidade e o reconhecimento de determinados grupos sociais, especialmente indigenas e negros.

Entre os grandes desafios que ainda persistem, sobremaneira, para as instituições educativas, é aprofundar o debate sobre os preconceitos existentes, bem como desconstruir mitos produzidos por setores da intelectualidade brasileira conservadora que escamotearam conflitos e contradições, além de idealizar aspectos socioculturais atribuidos ao povo brasileiro como ordeiro, paćífico, generoso e cordial. Sem a desconstrução desses mitos, reproduzidos em diferentes espaços e presentes em instituições e em práticas sociais, não há como avançar, pensar uma democracia efetiva.

A desconstrução desses mitos precisa vir acompanhada por uma reflexão qualitativa sobre os pressupostos de uma educação intercultural. É fundamental avançar no entendimento que a pluralidade é condição para uma vida democrática que, por sua vez, exige que aprendamos a viver com $\circ$ outro. Nesse horizonte, não cabe qualquer postura fundamentalista, xenofóbica ou discriminadora. Como bem destaca Benevides (1996, p. 223237), a escola é ainda um espaço privilegiado para a discussão e a formação democrática e cidadã. Entretanto, não basta essa possibilidade. É imprescindivel que professores e alunos assumam a responsabilidade de avançar na discussão sobre a formação histórica brasileira, os diferentes grupos étnico-culturais, as contradições e os preconceitos construídos e ainda reproduzidos na atualidade. Sem essa consciência aprofundada é dificil garantir os princípios constitucionais que ninguém pode ser discriminado.

Os avanços nas legislações, particularmente da educacional, ao estabelecer as diretrizes para a educação das relações étnico-raciais somente se tornarão realidade quando a sociedade como um todo encarar um debate aberto e transparente sobre as discriminações e as desigualdades que persistem nos salários, nos índices de criminalidade, nas condiç̃̃es de vida digna, no acesso e na permanência na educação básica e superior. 
Nesse sentido, é fundamental avançar na construção de práticas sociais democráticas, mas também adentrar os espaços científicos e acadêmicos de produção do conhecimento e de formação humana. Um grande desafio é, sem dúvida, fazer com que as experiências históricas silenciadas de diferentes formas ganhem visibilidade e, nessa pluralidade, possamos aprender e conviver juntos. Essa é a proposta política e epistemológica de Santos (2008, p. 93-135) quando propõe um duplo movimento a ser efetivado pela sociologia das ausências e pela sociologia das emergências.

\section{REFERÊNCIAS}

BAGNO, M. Preconceito linguístico: o que é, como se faz? 31. ed. São Paulo: Loyola, 2004.

BENEVIDES, M. V. Educação para a democracia. Lua Nova, São Paulo, n. 38, p. 223-237, 1996.

BOURDIEU, P. A dominação masculina. 3. ed. Rio de Janeiro: Bertrand Brasil, 2003.

BOURDIEU, P. Distinction. Cambridge: Harvard University Press, 1984.

BOURDIEU, P.; PASSERON, J. C. La reproducion. Paris: Minuit, 1970.

BRASIL. Câmara dos Deputados. Decreto-Lei n. 2.848, de 7 de dezembro de 1940. Código Penal. Rio de Janeiro, 7 dez. 1940. Disponivel em: http://www2.camara.leg.br/legin/fed/declei/1940-1949/decreto-lei-2848-7-dezembro-1940-412868-normaatualizada-pe.pdf. Acesso em: 11 abr. 2017.

BRASIL. Constituição. República Federativa do Brasil. Brasilia, DF: Senado Federal, 1988.

BRASIL. Lei n. 9.394. Estabelece as Diretrizes e Base da Educação Nacional. Diário oficial da União, Brasília, DF, 23 dez. 1996.

BRASIL. Lei n. 10.639, de 9 de janeiro de 2003. Altera a Lei n. 9.394, de 20 de dezembro de 1996, que estabelece as diretrizes e bases da educação nacional, para incluir no currículo oficial da Rede de Ensino a obrigatoriedade da temática "História e Cultura Afro-Brasileira", e dá outras providências. Diário Oficial da União, Brasília, DF, 10 jan. 2003.

CARVALHO, J. M. de. Os bestializados: o Rio de Janeiro e a república que não foi. São Paulo: Companhia das Letras, 1987.

CHAUÍ, M. Brasil: mito fundador e sociedade autoritária. 5. reimp. São Paulo: Perseu Abramo, 2004.

FERNANDES, F. A integração do negro na sociedade de classes. São Paulo: Ática, 1978a. v. 1.

FERNANDES, F. A integração do negro na sociedade de classes. São Paulo: Ática, 1978b. v. 2. 
FERNANDES, F. A revolução burguesa: ensaios de interpretação sociológica. Rio de Janeiro: Zahar, 1975.

FREYRE, G. Casa Grande \& Senzala. 25. ed. Rio de Janeiro: José Olympio Editora, 1987.

FREYRE, G. Sobrados e Mucambos: decadência do patriarcado rural e desenvolvimento do urbano. 2. ed. Rio de Janeiro: José Olympio, 1951a. v. 1.

FREYRE, G. Sobrados e Mucambos: decadência do patriarcado rural e desenvolvimento do urbano. 2. ed. Rio de Janeiro: José Olympio, 1951b. v. 2.

FREYRE, G. Sobrados e Mucambos: decadência do patriarcado rural e desenvolvimento do urbano. 2. ed. Rio de Janeiro: José Olympio, 1951c. v. 3.

HOLANDA, S. B. Raizes do Brasil. 27. ed. São Paulo: Companhia das Letras, 2014.

IBGE. Característica da população e dos domicílios. Rio de Janeiro, 2010. Disponível em: http://www. brasileirosnomundo.itamaraty.gov.br/a-comunidade/estimativas-populacionais-das-comunidades/ estimativas-do-ibge/censo-demografico-ibge-2010.pdf. Acesso em: 30 abr. 2017.

IBGE. Estatísticas históricas do Brasil. Rio de Janeiro, 1986. Disponível em: http://biblioteca.bge.gov.br/ visualizacao/monografias/GEBIS\%20-\%20RJ/seriesestatisticasrestrospectivas/Volume\%203_Estatisticas\%20historicas\%20do\%20Brasil_series\%20economicas_demograficas\%20e\%20sociais\%20de\%20 1550\%20a\%201988.pdf. Acesso em: 4 maio 2017.

IBGE. Rendimento médio real habitualmente recebido no trabalho principal, segundo a cor ou raça, por regiões metropolitanas. [S. l], 2013. Disponivel em: http://jornalggn.com.br/blog/rogeriobeier/ibge-negros-ganharam-57-do-salario-dos-brancos-em-2013. Acesso em: 2 jun. 2017.

INSTITUTO DE PESQUISA ECONÔMICA APLICADA. Desigualdades raciais, e racismo e políticas públicas: 120 anos após a abolição. Brasília, DF, 2008. Disponivel em: http://repositorio.ipea.gov.br/bitstream/11058/4729/1/Comunicado_n4_Desigualdade.pdf. Acesso em: 8 de mar. 2017.

NOGUEIRA, M. A. N.; CATANI, A. Pierre Bourdieu. Escritos em Educação. Petrópolis: Vozes, 1998.

SANTOS, B. de S. Uma sociologia das ausências e uma sociologia das emergências. In: SANTOS, B. de S. Gramática do tempo: para uma nova cultura política. 2. ed. São Paulo: Cortez, 2008.

SMARTLAB. Observatório digital do trabalho escravo no Brasil. Disponivel em: https://observatorioescravo.mpt.mp.br. Acesso em: 18 jun. 2017.

SOUZA, J. A construção social da subcidadania: para uma sociologia política da modernidade periférica. 2. ed. Belo Horizonte: Ed. UFMG, 2012.

SOUZA, J. Ralé brasileira: quem é e como vive. 2. ed. Belo Horizonte: Ed. UFMG, 2016. 
VIANNA, L. W. A revolução passiva: iberismo e americanismo no Brasil. Rio de Janeiro: Revan, 1997.

WAISELFISZ, J. J. A cor das vítimas. In: WAISELFISZ, J. J. Mapa da Violência 2015: Mortes Matadas por Armas de Fogo. Brasília, DF: Secretaria Geral da Presidência da República Secretaria Nacional de Juventude, 2015. Disponível em: http://www.mapadaviolencia.org.br/pdf2015/mapaViolencia2015.pdf. Acesso em: 5 jun. 2017.

WAISELFISZ, J. J. Mapa da Violência 2013: Homicídios e Juventude no Brasil. Brasilia, DF: Secretaria Geral da Presidência da República Secretaria Nacional de Juventude, 2013. Disponível em: http://www.mapadaviolencia.org.br/pdf2013/mapa2013_homicidios_juventude.pdf. Acesso em: 25 maio, 2017.

Endereços para correspondência: Rua Coronel Gabriel Bastos, n. 13, apto. 401, Bairro Vergueiro, 99020100, Passo Fundo, Rio Grande do Sul, Brasil; telmomarcon@gmail.com 